\title{
The Impact of Web-based Technology on Small Businesses
}

\author{
Courtney S. Baldwin \\ Correspondence: Courtney S. Baldwin, School of Business, Walden University, Minneapolis, Minnesota \\ Received: February 3, 2015 Accepted: February 10, 2015 Online Published: February 13, 2015 \\ doi:10.11114/bms.v1i1.681 \\ URL: http://dx.doi.org/10.11114/bms.v1i1.681
}

\begin{abstract}
:
The problem discussed in this paper is the need to understand ways to implement web-based technology to reduce the cost and time in doing business. The specific focus of this paper is to understand what the risks, challenges, and methodology are for implementing web-based technology for reducing the operating costs for the small business and still protect the security of the business. The key research questions included are: (a) What are the challenges of small business implementing web-based technology within their companies. (b) Which project methodology should be used to implement web-based technology projects in small business? (c) What are the risks and issues when implementing web-based technology in small business? According to the U.S. Small Business Administration (SBA, 2011), seven out of 10 new employer firms survive at least 2 years, half at least 5 years, a third at least 10 years, and a quarter stay in business 15 years or more. Besser (2012) wrote that small businesses are the vast majority of businesses and make a significant contribution to national economic vitality.
\end{abstract}

Keywords: innovation, project management, portfolio management, balance scorecard, SMEs

\section{Introduction}

According to Harris and Patten (2014) The United States Administration (SBA), Office of Advocacy, defines a small business as an independent business having fewer than 500 employees (SBA, 2011). However, for US contracting purposes, according to the USDL, businesses are considered small if they have under 100 employees and medium-sized with up to 500 employees.

Innovation in technology over the years have provided small and medium sized enterprises with better broadband internet access and new mobile technology tools, which increased and provides a new avenue to improve competitiveness with larger organizations (Harris and Patton 2012).

In today's world, poor communication with an organization can drive inefficiencies that can result in increased cost, economic brand issues, low employee morale, and loss of company's reputation (Hendershot, 2013). Small businesses are investing all over the world in web-based technology like mobile, cloud, and virtualization technology in order to assist in innovation, maintaining competitive advantage, and improvement of the daily operations process. For example, Taiwan is a country that has invested billions in the Taiwan National Telecommunication Department (Hung and Chou 2013).

Challenges can arrive when accepting internet and e-business technologies in small business. There are external factors that influence this implementation. One external factor is the perceived benefits of small businesses buying into how internet and e-business technologies can help the business. As internet and e-business technologies gain more popularity by other small businesses and customers, partners and competitors it is expected to push more reluctant small businesses into this new way of doing business (Ifinedo, 2011). This paper explores the potential impact of web-based technology on small businesses, by examining web-based technology challenges, possible research questions, risks of web-based technology in small business and some conclusions and implications of web-based technology and small businesses

\section{Web-based Technology Challenges}

Web-based technology does present problems for small businesses. According to Rahman and Ramos, (2013) there are four innovative constraints in SMEs that are categorized as human aspects, general and related to policies, and constraints that have evolved due to increased globalization and competition. Table-1 shows those constraints in four categories.

Table 1. Open innovation constraints in SMEs 


\begin{tabular}{|c|c|c|c|}
\hline Heman aspech & Genersil wantrainth & Policg conatrainh & Competitisn \\
\hline Scatify of willed anpponer & $\begin{array}{l}\text { Lack of mathet demabd (Low } \\
\text { pucharing power of custooer) }\end{array}$ & High enit af open itanevation & Therease quality of product wertice \\
\hline Searcity of noo-shilied mupower & Iack of akithad mapposer & Lack of finascing & Increase produer differentiunon \\
\hline Low inges of the peofessien & Top erpensite mapower & High ecooomes net & Look for moriket metbes (demund) \\
\hline Low inage of the sectoe & $\begin{array}{l}\text { Lack of crality aumapument } \\
\text { pevoenal }\end{array}$ & Otguisubional nqudities & Increase makietas activity \\
\hline Lew image af the tyse of etterpmie & 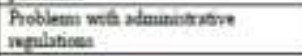 & Goversment regulatsods & Reduce coits of prodochies \\
\hline Wage Ievali too enpeanive & 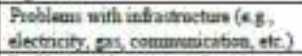 & Lack of embetast' mipeainksat & 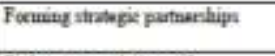 \\
\hline Unplazsant wouk & $\begin{array}{l}\text { Probleme with access to finewce } \\
\text { (other than internt ridev) }\end{array}$ & $\begin{array}{l}\text { Lack of hrowiedpr to wee new } \\
\text { tectanley }\end{array}$ & $\begin{array}{l}\text { Reduce prices (paices of } \\
\text { productihervices) }\end{array}$ \\
\hline Utglesant worting contithons & Hiph interest ntes & Lack of mformonoc oe murket & Incresse wonheng boun \\
\hline \multirow[t]{4}{*}{ No problem with recruiting } & 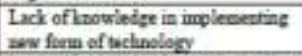 & \multirow[t]{4}{*}{ Dod not bave any manoritive plan } & Look for obet foreign markets \\
\hline & 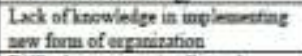 & & \multirow[t]{3}{*}{ Reduse produchon } \\
\hline & $\begin{array}{l}\text { Difliculf to protect asellectal } \\
\text { jropenty }\end{array}$ & & \\
\hline & $\begin{array}{l}\text { Did not bive any open inmorabon } \\
\text { fide }\end{array}$ & & \\
\hline
\end{tabular}

Note. From "Challenges in adopting open innovation strategies in SMEs" by H. Rahman and I. Ramos, 2013, Issues in Informing Science and Information Technology, 10. pp 435.

The challenges mentioned above are apparent to all small businesses. And this is the reason why a company's strategic mission, goals, and objectives are important.

Aligning a project, organizations mission, and key strategic initiatives we have to consider choice elements, which are vision, mission, objectives, goals, strategies, and facilitative services. Aligning the project, organizations mission, and key strategic initiatives is important because all these different elements are connected when it comes to managing an organization. "From an organizational perspective, completion of a project means that an organizational goal has been completed. Indeed, the breakdown of the choice elements for the enterprise where the relative position of the vision, mission, objectives, goals, programs, and projects could be considered a conceptual work breakdown philosophy for the strategic management of the organization" (Cleland, 2007, p. 70).

"Leading the organization to intended goals and objectives requires measurement of the current state or performance of actions, analyzing the gap between the current and intended state, and making corrective actions" (Morris and Pinto, 2007, p.7). In using web-based technology small businesses must also have a plan of action to achieve the results required this is where project management comes into play.

\section{Project Methodology Research Question}

To help with managing projects managers have different approaches they can use. One approach is the agile approach. The methodology is based on four values according to Holzmann and Panizel, (2013) they are:

1. Individuals and interactions over processes and tools

2. Working software over comprehensive documentation

3. Customer collaboration over contract negotiation

4. Responding to change over following a plan

To accomplish the implementation of web-based technology projects within a small business the researcher suggests an interactive approach especially since all small businesses are using web-based technology in one way or another. This will insure that there is a common theme being categorized. For instance, as the researcher observes the participant's patterns of behavior the researcher will establish relationships with the participants by engaging in their daily activities (Creswell, 2009).

The data collected could be open-ended face-to-face interviews and questions, observations, and audio-visual material. The data could include the following information: company size; annual revenue; operating costs; technology costs; importance of accessibility to confidential customer information during transit; technology skills set of the workers; view of outsourcing technology; and the view of sharing server space with other customers. The study could include a qualitative codebook to serve as a table of record that could contain a list of predetermined codes to gather information. The qualitative codebook could be created in Microsoft Excel.

However, since this study focuses on small businesses the responses to the open-ended face-to-face interviews and questions could be used to focus on how small businesses are overcoming web-based problems. The study should be based on different perspectives as it pertains to web-based technology and small businesses. One way to address 
different perspectives is by using the balanced scorecard.

According to Kaplan and Norton (2007), the balanced scorecard suggests that we view the organization from four perspectives, and to develop metrics, collect data and analyze it relative to each of these perspectives. These perspectives are:

1. The Learning \& Growth Perspective

2. The Business Process Perspective

3. The Customer Perspective

4. The Financial Perspective (Kaplan \& Norton, 2007).

The Learning \& Growth perspective includes employee training and corporate cultural attitudes related to both individual and corporate self-improvement. The Business Process Perspective refers to internal business processes. Metrics based on this perspective allow the managers to know how well their business is running, and whether its products and services conform to customer requirements (the mission). The Customer Perspective involves the customers analyzed in terms of kinds of customers and the kinds of processes for which products and services serve the customer groups. And the financial perspective explains the need to include additional financial-related data, such as risk assessment and cost-benefit data, in this category.

The balanced scorecard is a management system that allows organizations to describe their vision and strategy and translate them into action it also provides feedback on the internal business processes and external outcomes to improve strategic performance and results (Kaplan and Norton, 2007).

Monitoring and control phase should lead to dynamic scheduling and real-time reporting of the management of the project and any possible changes, and issues (Morris and Pinto, 2007). In the real estate world, monitoring and controlling phase could hold a number of definitions, such as updating and maintaining the themes table with constant communication with the SREBEs for validation of the data. The closure phase of a project refers to the contractual or strategic closeout and should be created during the planning phase (Morris and Pinto, 2007). With relation to the real estate company, the close out of the study is appropriate with hand-off copies of the data collected, forms completed, codes and themes created, and answers to all transcribed interviews conducted and final sign-off from the key stakeholder/sponsor - broker and agents.

\section{Risks of Web-based Technology in Small Businesses}

\subsection{Security Attacks}

One of the biggest risks of using web-based technology that small businesses face is security attacks. According to Zhao,Xue, and Whinston, 2013) a typical example of a negative security risk is a targeted attack. A targeted attack refers to a malware attack aimed at one firm or a small set of firms. Strategic hackers often evaluate the security level of firms using various hacking techniques, such as port scans or eavesdropping, and select as their target firms whose systems can be broken into. This is where project portfolio management comes into play. "Leading the organization to intended goals and objectives requires measurement of the current state or performance of actions, analyzing the gap between the current and intended state, and making corrective actions" (Morris and Pinto, 2007, p.7).

In order for PPM to be successful Pennypacker and Retna (2009) suggests that a company should explore five questions:

1. Are we investing in the right things?

2. Are we optimizing our capacity?

3. How well are we executing?

4. Can we absorb all the changes?

5. Are we realizing the promised benefits? (Pennypacker and Retna, 2009, p 4-5).

Project managers in a small business should be asking themselves are they investing in the right things to mitigate security risks. In small businesses, the customers are the most important part of the business. Securing customers confidence and trust is vital to gaining and retaining customers. In today's competitive marketplace, that is more difficult to do than ever. Being able to keep customer sensitive data secure and safe is a very important step in keeping your company profitable. Intro to Small Businesses states that in fact, Verizon reports that approximately $40 \%$ of data breaches in 2012 occurred among companies with fewer than 100 employees.

This is perhaps where innovation and project management comes into play, According to Gray and Larson (2008) there are two dimensions within the project management process the first dimension is the technical side and the second dimension is the sociocultural side of the project management process. The technical side includes planning, scheduling, 
and controlling projects. The sociocultural side centers on creating a social system within an organizational environment that combines the talents of professionals working to complete the project (Gray and Larsen, 2008).

Small businesses definitely have to innovate how they incorporate web-bases technology into their systems in order to make sure the information given by the customer is secure and the information that they give the customer is secure. Legrand and David (2011) states that there are two factors that create an innovation gap in organizations. The first is knowledge. Knowledge presents a problem because leaders do not know how to make innovation systematic. The second is that organizations are still using the same systems that made organizations successful in the industrial economy versus a knowledge based economy. Not being able to use or find the correct knowledge needed for the organization and using outdated systems. Innovative thinking skills can positively influence project management by bringing creativity to the project. Gemünden; Killen and Kock (2013) states that the importance of innovation project management is escalating in an increasingly competitive, globalized, and dynamic environment, in which innovation is the primary driver of firm survival and growth. In innovation managers should be looking at certain capabilities. According to Bessant, Pavitt, and Tidd (2005) there are core capabilities in managing innovation:

- Recognizing

- Aligning

- Acquiring

- Generating

- Choosing

- $\quad$ Executing

- Implementing

- Learning

- Developing the organization

\subsection{Risk Avoidance}

Risk avoidance involves changing the project management or isolating the project to change the objective that is at risk to eliminate a threat. This could lead to a manager extending a schedule or changing the strategy. Some risk avoidance techniques involve understanding the requirements, obtaining information, improving communication or acquiring expertise. For example in small businesses if the web-based technology to be used for operations does not align with the project strategy then leadership can either change or change the objective to reach its goal. This strategy avoids the aggregation of risks associated with placing excessive value in one place. (Project Management Institute, 2009). Another way a small business can potentially avoid risk is by having an innovative plan in place. According to Legrand and David (2011) there are six guiding principles for developing an innovation plan. These principles ensure that the plan is solid, sustainable, and will achieve the objectives:

- Focus on clear business objectives

- Engage the whole executive team

- Top-down but open to bottom-up input

- Include clear boundaries

- Resource and enforce the plan

- Include metrics to track progress

\subsection{Risk Transference}

Risk transference involves making another party responsible for the risk by purchasing insurance, performance bonds, warranties, guarantees, or outsourcing the work. This is where there is a strong connection between risk and procurement. For example, if a small business purchase software from a company but does not have the knowledge or capability to make the product work then it would make since for the company to transfer liability of this phase of the implementation of the new product. (Project Management Institute, 2009).

\subsection{Risk Mitigation}

Risk mitigation suggests that the impact or probability can be reduced within acceptable threshold limits. Taking steps to reduce the probability of a risk occurring before something actually happens is more effective than waiting for something to happen. Examples of possible mitigation techniques involve tests, and less difficult processes. When it is not possible to reduce the probability mitigation process the risk maybe addressed by targeting the connections that determine the severity (Project Management Institute, 2009). One of the ways that a small business can mitigate risk is 
by mangers taking a project managers approach. According to Legrand and David (2011) executive leaders must clarify what they want to achieve with innovation, and understand what prevents teams from reaching innovation. Executive leaders also have strong commitment to innovation. Clarifying what is to take place, understanding the people or groups involved in the process, and commitment are all leadership skills that a person in a leadership position must bring to the table. These types of skills are needed because it drives the seven major characteristics of a culture of innovation that leaders need to enable. According to Legrand and David (2011) These seven major characteristics are:

- Everyone understands the organizational direction.

- Innovation is a priority.

- Executive team models innovative thinking and innovative practices.

- Open and honest communication and trusting relationships.

- Effective cross-functional teams that encourage diverse viewpoints.

- $\quad$ Leaders who engage in risk-taking focused on delivering value.

- Balance innovative thinking with the discipline to implement solutions.

\subsection{Risk Acceptance}

Risk acceptance involves a decision by management to accept a given risk without further mitigation or transfer, for a period. This happens in two classes of circumstances. For risks that are too low to bother protecting against or for which insurance and due diligence are adequate, risk is accepted. For risks that are to be mitigated but where mitigation cannot be done instantaneously or for which rapid mitigation is too expensive to warrant, risks are accepted for periods during which mitigation is undertaken (Project Management Institute, 2009)

The risks for small business appear to be the inability to understand what to look for and what is needed in order to implement we-based technology appropriately. Small businesses should focus on identifying those risks and determine ways to avoid, mitigate, transfer, or accept the risks.

The need for constant monitoring with their clients is paramount for the small businesses.

\section{Conclusions and Implications}

Web-based technology if implemented correctly can reduce the cost of small businesses allowing small businesses to provide jobs and produce a better quality of living for its community. Small businesses play a very important role in creating jobs. According to the U.S. Small Business Administration (2011), seven out of 10 new employer firm survive at least 2 years, half at least 5 years, a third at least 10 years, and a quarter stay in business 15 years or more. Besser (2012) stated that small businesses are the vast majority of businesses and make a significant contribution to national economic vitality. Their value to the survival of small towns, where they are often the only businesses, is even more important.

Small businesses play a big part in their local economies by providing job opportunities for workers who would not qualify to work at larger corporations. Small businesses tend to attract talent who invent new products or implement new solutions for existing ideas. Larger businesses also often benefit from small businesses within the same local community, as many large corporations depend on small businesses for the completion of various business functions through sub-contracting or outsourcing.

\section{References:}

Bessant, J., Pavitt, K., \& Tidd, J. (2005). Managing innovation. Integrating technological, market and organizational change. (3rd ed., pp. 85-86), Hoboken, NJ: John Wiley \& Sons.

Besser, T. L. (2012). The consequences of social responsibility for small business owners in small towns. Business Ethics: A European Review, 21(2), 129-139. http://dx.doi.org/10.1111/j.1467-8608.2011.01649.x

Cleland, D. I. (2007). Strategic management: The project linkages. In P. W. G. Morris \& J. K. Pinto (Eds.), The Wiley guide to project, program \& portfolio management (2nd ed., pp. 63-79). Hoboken, NJ: John Wiley \& Sons.

Creswell, J. W. (2009). Research design: Mixed method, quantitative, and mixed methods approaches (3rd ed.). Thousand Oaks, CA: Sage.

Gray, C., \& Larson, E. (2008). Project Management. The managerial process 4 ed., NY: McGraw-Hill Companies, Inc.

Gemunden, H. G., Killen, C., \& Kock, A. (2013). A special issue of creativity and innovation management: Implementing and informing innovation strategies through project management. 22 (1), 103-104. 
Harris, A. M., \& Patten, P. P. (2014). Mobile device security considerations for small- and medium-sized enterprise business mobility. Information Management \& Computer Security, 22 (1), 97-114. http://dx.doi.org/10.1108/IMCS-03-2013-0019

Hendershot, S. (2013). The Mobile Mindset. PM Network, 27(5), 47-49.

Holzmann, V., \& Panizel, I. (2013). Communications management in scrum projects. Proceedings of the European conference on information management \& evaluation, 67-74.

Hung, C., \& Chou, J. C. (2013). Resource Commitment, Organizational Diversity and Research Performance: A Case of the National Telecommunication Program in Taiwan. Project Management Journal, 44(3), 32-47. http://dx.doi.org/ 10.1002/pmj.21340

Ifinedo, P. (2011). Internet/e-business technologies acceptance in Canada's SMEs: An exploratory investigation. Internet Research, 21(3), 255-281. http://dx.doi.org/10.1108/10662241111139309

Kaplan, R. S., \& Norton, D. P. (2007). Using the balanced scorecard as a strategic management system. Harvard Business Review.

Legrand C., \& David, S. D. (2011). How leaders can close the innovation gap. Ivey Business Journal. Retrieved from http://www.iveybusinessjournal.com/topics/innovation/how-leaders-can-close-the-innovation-gap

Morris, P. W. G., \& Pinto, J. K. (2007). The Wiley guide to project, program \& portfolio management. (pp. 55). Hoboken, NJ: John Wiley \& Sons.

Pennypacker, J., \& Retna, S. (Eds.). (2009). what is project portfolio management? In Project portfolio management: A view from the management trenches 1-24. Project Management Institute. Retrieved from http://www.gartner.com/it/content/911400/911412/project_portfolio_mgmt_excerpt.pdf.

Project Management Institute (2009). A Guide to the Project Management Body of Knowledge (PMBOK Guide) (4th ed., pp. 9). Project Management Institute.

Rahman, H., \& Ramos, I. (2013). Challenges in adopting open innovation strategies in SMEs: An exploratory study in Portugal. Issues in informing science and information technology, 10, 431-448.

U. S. Small Business Administration. (2011). Strategic plan and updates. Retrieved from http://sba.gov

Zhao, X., Xue, L., \& Whinston, A. B. (2013). Managing Interdependent Information Security Risks: Cyberinsurance, Managed Security Services, and Risk Pooling Arrangements. Journal Of Management Information Systems, 30(1), 123-152. http://dx.doi.org/10.2753/MIS0742-1222300104

\section{(c) EY}

This work is licensed under a Creative Commons Attribution 3.0 License. 